\title{
Can emotion acceptance-based interventions alleviate depression symptoms and alcohol consumption?
}

\section{Alfath Hanifah Megawati ${ }^{\mathrm{a}}$ and Bona Sardo Hasoloan Hutahean ${ }^{\mathrm{b}}$}

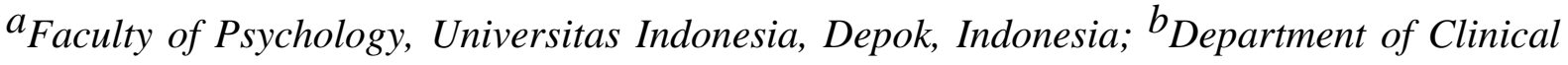
Psychology, Faculty of Psychology, Universitas Indonesia, Depok, Indonesia

*Corresponding author:

Bona Sardo Hasoloan Hutahean

Department of Clinical Psychology

Faculty of Psychology, Universitas Indonesia

Jl. Lkr. Kampus Raya, Depok, Jawa Barat

Indonesia, 16424

Tel.: +62 217270004

Email address: bonasardo@ui.ac.id / sardo.bona@yahoo.com 


\title{
Can emotion acceptance-based interventions alleviate depression symptoms and alcohol consumption
}

\begin{abstract}
Depression and alcohol abuse are interrelated disorders. Many people use alcohol to suppress their negative emotions and feel better in stressful situation. However, alcohol abuse has negative impacts that can lead to alcohol dependence and health problems. The current study was a single-case study with repeated measurements $(n=1)$ in which intervention used couseling methods adapted concepts of Acceptance and Commitment Therapy (ACT), including being present, acceptance, and commitment. The intervention was conducted infour sessions. The study examined the effectiveness of the intervention in a client who had reported various depression symptoms along with alcohol abuse as a means to suppress negative emotions. The participant was B, a 20-year-old woman, with a history of bulimia and alcohol abuse who came to the counseling center with complaints of stress and feelings of prolonged sadness. The results of the intervention included a decrease of depression symptoms as reflected in ad reduction of Beck Depression Inventory (BDI) measurements from 25 to eight and ad decrease of self-reported alcohol consumption from eight to zero times per month. Mindfulness breathing helped her to cope with perceived negative emotion. Counseling technique helped B to understand herself and her primary emotions. Moreover, observation tasks given as homework helped B to be more clearly aware of her emotions, thoughts, and situation. These conditions helped B to enhance her mood and re-engage in daily activities, which was followed by a desire to take action in improving her interpersonal relationships, particularly with her parents. Her success in dealing with her negative emotions and improving her interpersonal relationships reduced B's use of alcohol consumption as emotional coping. Nevertheless, difficulties with decision-making that were reported in a follow-up session should be the focus of future interventions.
\end{abstract}

Keywords: depression, alcohol abuse, negative emotion acceptance

\section{Introduction}

The college years are a time of tansition from late adolescence to early adulthood, which Arnett (2011) labelled as "emerging adulthood". In emerging adulthood, an individual experiences increasing demands to fully become an adult, however they have limited ability to be actually independent. This dilemma makes emerging adulthood a vulnerable period for individuals and is a potential risk that can trigger the emergence of various psychological disorders, such as depression. At 25\%, the prevalence of depression in 18-25 year-olds is quite high compared to other age groups (Kuwabara, Van Vorhees, Gollan \& Alexander, 2007). Later in life, this condition becomes one of the risk factors associated with the emergence of alcohol abuse.

Depression and alcohol abuse are problems that require further attention in Indonesia. The two disorders are closely associated, as alcohol abuse is almost always preceded by mild or moderate depression symptoms (Sacks, Ries \& Ziedonis, 2005). Many people use alcohol because it is considered a means of coping with depression, as it can help to suppress their 
negative emotions and feel better in stressful situations. Nonetheless, alcohol abuse has negative impacts that can lead to alcohol dependence and health problems. Past studies have demonstrated that alcohol can trigger or worsen depression symptoms and lead to permanent devastating consequences. The severity of alcohol abuse in an individual is associated with depression severity, and vice versa (Gilman \& Abraham, 2001; Pettinati \& Dundon, 2011; Regier, Farmer \& Rae, 1990). Moreover, alcohol abuse prolongs the course of depression, and persistent depression during abstinence from alcohol is a risk factor for relapse to heavy drinking (Hasin, Tsai \& Endicott, 1996; Pettinati \& Dundon, 2011). The two disorders carry significant risks for the development of each another. Accordingly, logic dictates that both disorders be identified and managed concurrently (Hasin et al., 1996).

Depression is defined as an emotional state marked by great sadness, feelings of worthless and guilt, withdrawal from others, loss of sleep and appetite, loss of sexual desire and interest, and feelings of pressure concerning usual activities (Davidson \& Neale, 2001; Forrest, 1983). Although a number of researchers have attempted to define this mood condition, the symptoms and signs of depression vary across the lifespan (Davidson \& Neale, 2001). Depression is not always necessarily a sign of a pathological mental state, but rather can be a normal reaction to loss, struggles of life, or an injured self-esteem. However, situational depression can develop into clinical depression if its duration lasts for many days or weeks and it begins to hinder an individual's ability to function normally.

Depressive disorder needs to be treated appropriately because it often leads to mortality. Currently, many cases of death in Indonesia are related to depression. According to the results of basic medical research (Riskesdas, 2013), the prevalence of mental emotional disorder as indicated by symptoms of depression and anxiety is approximately 14 million people, or $6 \%$, for individuals aged 15 and over. The data also shows that in Indonesia, only $8 \%$ of people with depression seek treatment, whereas the remaining $92 \%$ do not receive proper and/or necessary care.

Depression can be caused by high stress levels associated with life events (Plieger, Melchers, Montag, Meermann \& Reuter, 2015). Stress in college students is not only related to academic demands, but also to problems with peer and family relations. An inadequate ability to regulate emotion can turn stress symptoms into depression. Sustained stress leads to elevated levels of the stress hormone cortisol and reduced dopamine, both of which have been linked to depression. As maintained by the diathesis stress theory proposed by Linehan (1993, cited in Reeves, 2007), family relations are also a major cause of poor development of emotion regulation in individuals, whereby the experience of repeated emotional invalidation in childhood (i.e., punishment due to children's subjective emotional experiences) leads to a decrease in the ability to regulate one's emotions in adulthood. Such invalidation sourced in family life can develop into sustained stress in the adult individual and eventually cause an uncontrolled emotional outburst during a stressful life event.

Emotion regulation is an essential component in an individual's life adjustment. The lack of this ability can lead someone to a mental problem, such as depression and substance abuse (Cole, Michel \& Teti, 1994; Forkman et al., 2014; Joorman, 2010; Compare et al., 2014). Emotion regulation is defined as the ability to respond with the range of emotions to the 
ongoing demands of experience in a manner that is socially tolerable and sufficiently flexible to permit spontaneous reactions, as well as the ability to delay the necessary spontaneous reactions (Cole, et al., 1994). Under certain conditions, patterns of emotion regulation jeopardize or impair functioning, and basic emotion patterns can develop into patterns that interfere with functioning (Cole, Michel \& Teti, 1994). Depressed and non-depressed individuals might not differ much in their initial response to a negative event (Rottenberg, 2007), but rather vary in the degree to which they are able to repair their mood once they experience sadness or other negative emotions (Joormann, 2010).

As mentioned above, symptoms of both depression and alcohol consumption are associated with difficulties in emotional regulation. The cognitive approach is a common psychotherapy method used to improve emotion regulation. Cognitive theory and research have long supported the premise that the way a person thinks powerfully shapes what that person feels. Some studies related to the cognitive approach have found that emotion regulation can be improved through expressive suppression (Forkman et al., 2014), acceptance of the emotional experience (ACT; Hayes, Strosahl, \& Wilson, 1999; Wolgast, Lundh, \& Viborg, 2011), and cognitive reappraisal such as changing the core beliefs and consequences of behavior (Boden \& Gross, 2013; Forkman et al., 2014). These strategies are applied most notably in Acceptance and Commitment Therapy (ACT) (Hayes et al., 1999), which is typically applied over an extended period of time and ideally involves conducting one session of its six core concepts (Harris, 2009; Hayes, et al., 2011).

Researchers of the current study attempted to use ACT strategies in their counseling sessions over a relatively brief duration. The main focus of the sessions in the current intervention was to help the client identify, accept and come to terms with negative emotions, identify the relationship between each part of her system and her social experiences, and learn simple behaviors as part of her commitment to change. The negative emotions confronted by the client took the form of sadness, shame, or anger, and this study adapted the alternative behavior concepts emobodied in ACT, being present, acceptance, and commitment (Harris, 2009; Hayes et al., 2011).

It is important to establish a brief intervention period that can be applied as first aid to overcome initial symptoms of depression, thus avoiding clinical depression. The purpose of this study was to evaluate the effectiveness of a brief intervention in a client who, despite not having been clinically diagnosed with major depressive disorder, reported various symptoms of depression as well as alcohol abuse to suppress negative emotions.

\section{Case Presentation}

\section{Complaints}

At the time of the study, B was a 20-year-old woman who was registered by her friend into the college counseling service center, at University of Indonesia. It was her first experience coming to a counseling center and she arrived at the first session with a pale face and wearing a black suit. She was crying during the first session, which lasted about three hours. She elaborated on her conflict with her parents and spoke of a romantic relationship that made her 
feel unloved. She claimed that the only thing that made her feel self-confident was music, however thoughts of her ex-boyfriend and her anger towards her parents always disturbed her concentration. She reported feeling messy and becoming more frustrated when she failed at playing a piece of music or at composing a song. As she stated, "my life makes me believe that I need to be sad, then I feel sad in my everyday life. I always feel sad". She expressed that whenever she felt depressed, suicide ideation emerged. B also reported a history of bulimia when she was in high school and reported recent alcohol abuse when she experienced negative emotions.

\section{Background information}

B was the second of three children and the only daughter in her family. In each session, B discussed her disappointment in her family. B felt distanced from her family, and reported feeling more comfortable spending time alone in her room or going out with her friends until past midnight. This habit often triggered the conflict between $B$ and her parents.

In the early session, B discussed about bad memories of childhood with her father, who would drag her by holding her hair when annoyed with her. According to $\mathrm{B}$, her father was a cold and rude persion, who did not respect her as he valued his son, and tended to ignore her opinion because she is a woman. B often argued verbally with her father. When this occurred, her mother usually cried and begged her father to stop the fight. For B, her mother was a submissive housewife. When B was at home, her mother rarely invited B to talk and preferred to spend time her time by playing on her cell phone. In fact, her mother often communicated with B via chat even when both of them were at home. However, when B was outside of the house, her mother was very worried about her and demanded that B always update her on her activities. If B did not reply to her chats, then her mother would send messages to many of her friends in search of her. B's mother's behavior greatly bothered and embarrassed her.

B's oldest brother was a superior figure, who was free to do activities outside the house without being subjected to parental rules. B also often quarreled with her brother. According to $\mathrm{B}$, her brother also consumed alcohol without the knowledge of their parents. B's younger brother was the most reserved person in the home--and B often vented her anger, towards her parents and older brother to him. B said that her younger brother had attempted suicide. The incident made B felt guilty and led her to change her attitude towards him. Now, her younger brother was the only family member who was close to B. B often shared her days with her younger brother, but her brother remained introverted with anyone at home.

B had many relationships with men and avoided close emotional relationships. She stated that she felt more comfortable making friends with men than women, and that she had difficulty in controlling her anger when she felt uncomfortable with others. On the other hand, she always tried to be a cheerful friend. In romantic relationships, she tended to display cold behavior; however, in fact, she wanted to be noticed by her partners. During junior high school, she began smoking cigarettes, and her cigarette consumption increased throughout college. In high school, she had a history of an eating disorder, whereby she purged the food 
she consumed. During college, B started began consuming alcohol every weekend, particularly when experiencing negative emotions.

Two weeks before the first session, B had shut herself in her room for three days. During her confinement, she cut off communication with her friends, lost her appetite, constantly wept, thought about problems with her ex-boyfriend, felt worthless, and desired to kill herself. One of her friends had critized her body appearance the day before she had cut off communication from all of her friends. She reported that she had felt depressed up until the day she came into the counseling service center.

About half a year before coming to counseling, B had broken up with her boyfriend, which made her feel sad and insecure. She became easily upset when other people criticized her. She also had a history of family problems involving verbal and physical altercations with her father and feeling neglected by his mother. As a daughter, she felt unloved by her parents, and she said that almost always felt worthless and helpless. She thought there was no place that would accept her. Because she often felt sad, she thought that perhaps she was a person who always needed to be sad. She additionally reported having abused alcohol while experiencing negative emotions.

\section{Methods}

\section{Design}

The current study was a single-case study with repeated measurements, which were conducted during the first session (pre-test) and the last session (post-test). The intervention was performed in four sessions, each lasting 2-3 hours. The sessions were conducted over 3-7 days intervals. The intervention was performed over a total span of approximately three weeks.

\section{Context}

The intervention was conducted in the college counseling service center of University of Indonesia, Depok City. Each intervention sessions were performed in a counseling room with an individual setting.

\section{Approvals}

The participant agreed to have the process and the data obtained from the intervention process recorded and published in an educational setting. The counselor (the first author) ensured the confidentiality of the participant's identity by keeping it anonymous in all publication data. The counselor explained the purpose of each session and performed debriefing at the end of each session. The participant signed the provided informed consent. The counselor also provided the participant with a token of appreciation for her willingness to participate in the study. During the intervention process, the counselor was under the supervision of a psychologist (the second author) who also served as a supervising lecturer to the counselor. 


\section{Measures}

Depression Symptoms. Symptoms of depression were measured with the Beck Depression Inventory (BDI) (Beck, Steer, Beck \& Newman, 1993), a 21-question multiple-choice selfreport inventory that was adapted into the Indonesian language. BDI is one of the most commonly used self-report instruments for measuring the severity of depression. This scale evaluates various symptoms of depression including mood, pessimism, sense of failure, selfdissatisfaction, guilt, punishment, self-dislike, self-accusation, suicidal ideas, crying, irritability, social withdrawal, indecisiveness, body image change, work difficulties, insomnia, fatigability, loss of appetite, weight loss, somatic preoccupation, and loss of libido (Beck et al., 1993). The total score indicates whether the individual presents a mild, moderate, or major depression. The recommended cutoff score for mild mood disturbance is $11-20$, that for moderate depression is $21-30$, that for severe depression is $31-40$, and extreme depression is denoted by a score above 40 .

Alcohol Abuse. Alcohol abuse was measured by self-report of the frequency and quantity of alcohol consumption each week. In the first session, the participant was asked to count the number of times alcohol was consumed and to estimate how much alcohol was consumed during the past month. To provide a base of comparison, the participant was asked to provide the frequency of alcohol consumption throughout the intervention process.

\section{Intervention}

\section{First Session}

During the first session, baseline measures were obtained by asking the participant to fill out the BDI scale and to report alcohol consumption. After the participant filled the measurement scale, the counselor asked about the participant's problem. The first session was designed such that the participant would express suppressed negative emotions, and the counselor applied basic methods of counseling, such as asking open-ended questions, applying active listening, and providing a reflection of feeling and meaning related to the participant's story. At certain points, the counselor tried to validate the participant's reported emotions by assuring the participant that her feelings were acceptable and normal in certain kinds of situation.

At the end of the session, the counselor taught the participant to perform a mindfulness breathing technique and asked her to try to practice it at home as homework. The counselor instructed the participant to practice delayed response along with the mindfulness breathing. B was also encouraged to perform other exercises to help her calm down. Another homework assignment sought to heighten the participant's awareness of her feelings. The counselor asked B to note the feelings that emerged each day, including both negative and positive feelings, and to recognize the relevant situations in which they occurred. 


\section{Second Session}

The second session was designed to acquire the participant's life history. At the beginning of the second session, the counselor asked if there was anything that the participant wanted to share with the counselor. During this session, the counselor used the same technique as during the first session and asked the participant to reflect on her feelings while performing the homework assigned to her during the past session. The second session was conducted three days after the first session.

At the end of the second session, the counselor asked the participant to observe her parents' various at home routines rather than just focusing on things that inconvenienced her. The counselor also asked the participant to continue working to recognize her emotions and to consider her parents' perspectives based on her own observation.

\section{Third Session}

The third session was designed to help the participant realize the connection between her earlier and current problems. Again, the counselor used the same technique used in prior sessions. As before, the counselor also asked for the participant's reflections on what she had felt while doing the assigned homework. However, unlike in the previous session, the counselor applied a confrontation technique more frequently during this session. The counselor also encouraged the participant to try to see things from other possible points of view that might differ from her, and helped the participant to elaborate on other (negative) feelings she experienced when she was with her parents. The participant was then asked to recount specific situations in which she felt comfortable with her father and mother. The third session was conducted four days after the second session. At the end of the session, the counsellor asked the participant to once again pay attention to the various emotions she felt in the following days and the specific situations that triggered the feelings.

\section{Fourth Session}

The last session was designed to induce the participant to make a commitment to change, and additional exercises were assigned, as described below. The session was designed as a final session; therefore, the participant was asked to fill the same measurement scales that she had completed during the first session. The last session was conducted about approximately one week after the third session.

A total of four exercises were assigned to the participant during the session. The first exercise, asked the participant to make a diagram that reflected the pattern of her relationships among situations, her thoughts, and emotions, and the responses she experienced. The second exercise asked the participant to illustrate the cycle of complaints that initially drove her to come to counseling service. The third exercise focused on the participant's father and mother as the targets in the sequence. Specifically, the counselor asked the participant to list three positive things and three negative things about her parents. For the last exercise, the counselor asked the participant to write three simple things that she wanted to do with her parents and three simple things that she wanted her parents to do to her. At the end, the counselor asked the participant to write one word that could adequately 
describe the meaning of her parents in her life. Before the termination of the session, the participant was asked to fill the BDI scale and to report her alcohol consumption as post-test data.

TABLE I. TABLE OF SESSION

\begin{tabular}{|c|c|c|c|}
\hline Session & Technique & Result & Homework \\
\hline 1 & $\begin{array}{l}\text { Active } \quad \text { listening, } \\
\text { reflection, and validation } \\
\text { feelings; practiced } \\
\text { mindfulness breathing }\end{array}$ & B felt relieved & $\begin{array}{l}\text { Exercise mindfulness } \\
\text { breathing or another } \\
\text { exercise that made her } \\
\text { feel calm; the emotional } \\
\text { awareness }\end{array}$ \\
\hline 2 & $\begin{array}{l}\text { Reviewed the } \\
\text { homework; provided } \\
\text { active } \\
\text { reflection, and validation } \\
\text { feelings }\end{array}$ & $\begin{array}{l}\text { B realized that she } \\
\text { obfuscated her anger } \\
\text { with sadness; found } \\
\text { that she felt peaceful } \\
\text { while praying and } \\
\text { perfoming yoga } \\
\text { exercises. }\end{array}$ & $\begin{array}{l}\text { Observe her family and } \\
\text { consider the reasons } \\
\text { underlying their behavior }\end{array}$ \\
\hline 3 & $\begin{array}{l}\text { Reviewed the } \\
\text { homework; confronted } \\
\text { the conclusion; led } \\
\text { participant to consider } \\
\text { other points of view; } \\
\text { helped participant to } \\
\text { elucidate her other } \\
\text { feelings; asked } \\
\text { participant to recount } \\
\text { specific situations that } \\
\text { made her feel } \\
\text { comfortable with her } \\
\text { father and mother }\end{array}$ & $\begin{array}{l}\text { B realized that she } \\
\text { had many happy } \\
\text { moments with her } \\
\text { parents; found that } \\
\text { simple changes in } \\
\text { behavior might help } \\
\text { her to improve her } \\
\text { relationship with her } \\
\text { parents; re-engaged } \\
\text { in planning activities } \\
\text { with friends. }\end{array}$ & $\begin{array}{l}\text { Be aware of various } \\
\text { emotions that she felt } \\
\text { during her days and } \\
\text { notice the specific } \\
\text { situations that triggered } \\
\text { the related feelings }\end{array}$ \\
\hline 4 & $\begin{array}{l}\text { Reviewed the } \\
\text { homework; exercises on } \\
\text { relationship patterns and } \\
\text { related complaints; } \\
\text { induced a commitment to } \\
\text { change behavior; } \\
\text { psychoeducation about } \\
\text { emotions }\end{array}$ & $\begin{array}{l}\text { B planned simple } \\
\text { behaviors to repair } \\
\text { her relationship with } \\
\text { her parent; realized } \\
\text { the meaning of her } \\
\text { parents in her life; } \\
\text { reported that she felt } \\
\text { more comfortable } \\
\text { when she was with } \\
\text { her parents }\end{array}$ & Not assigned \\
\hline
\end{tabular}

\section{Follow-up Session}

A follow-up session was conducted via an online chat application. During the online interview, the counselor specifically asked about the participant's current conditions, including the positive changes she had made and any difficulties she still experienced. 


\section{Results}

\section{First Session}

Based on the results of the first measurement (pre-test), B was found to have a moderate level of depression with a score of 25 on the BDI. The participant also reported having consumed alcohol eight times (approximately four glasses per consumption incident) during the previous month. B thoroughly expressed her feelings and her thoughts, adding that it was her first time talking about her own feelings and thoughts. In her daily life, she tried to be a cheerful person at all times, which she claimed was why she always avoided a friend whenever she felt uncomfortable or unintentionally hurt by them. Recounting her worries about her future, she said, "I am afraid that I will always feel sad in my life. I am afraid that one day it will become a danger for my own children. I don't want to behave in the same way that my parents treat me. I want to get rid of this negative feeling". At the end of the session, $\mathrm{B}$ reported that she felt quite relieved to have expressed her feelings.

\section{Second Session}

During the second session, B shared about early life experiences in her family, her family's daily routine, her dreams to become a famous singer, and her desire to make people happy with her singing. Specifically, she wanted to express her sadness through songs, which she hoped would entertain many people on a certain level.

Over the few days following the first session, B realized that almost all of her energy over the course of her days was expended on negative emotions such as anger. This anger was intolerable to her and was therefore something she was unable to openly express. She realized that her anger was caused by her relationship with her parents, particularly her father. As a child, she had learned that the more she exhibited her anger, the more she was hurt. Although the situation made her sad, she realized that rather than feeling sad all the time, she actually felt angry most of the time that she spent at home. This in turn caused her to easily feel hurt while in her peer group. According to B, "I cannot contain my anger anymore when someone criticizes me. So when my friend told me that I was fat, it made me so angry".

Although B claimed that she had never been capable of calming herself down in the past, she reported feeling better as a result of the mindfulness breathing she had practiced at home. Similarly, she had found peace while she was praying and performing yoga exercises.

\section{Third Session}

During this session, B discussed her parents more extensively. She spoke about her early family history and her family's situation at the time she was born. She saw the connection between her parents' behavior and their life burdens. She said that she knew that both her parents loved her, acknowledged that they tried to fulfill her needs despite all of their challenges. However, B also felt unloved; she stated that her father underestimated her as a daughter and her mother was more concerned with her mobile phone than her own daughter. 
B realized she had spent many happy moments with her parents. She revealed her feelings when she tried to put herself in her parents' shoes and imagine what it would be like to have a child like herself. She said that she like her parents, she probably would have also been disappointed. B reported that she had found that slight changes in her daily behavior could improve her relationship with her parents. She acknowledged that she should not be protracted with her negative feelings and stated that she should re-engaging in planning fun activities with her friends to recharge her mood.

\section{Fourth Session}

While performing the first exercise, B found that her responses to her parents often triggered a worse situation that generated even more negative emotions. Her response would impact her parents' responses and vice versa. Based on the second exercise, B found that she always covered up her anger with sadness, and that her suppressed anger at her family could impact her relationships with other people. The counselor asked her to identify an alternative action that could possibly reduce her anger. B spoke of engaging in calming activities, such as deep breathing, praying, and participating in music. During the third simulation, B realized that her father exhibited behaviors that were quite similar with behaviors of her own that she viewed in a negative light, such as being inconsiderate, easily upset, and ungentle. B wrote of simple behaviors that she wanted to change, such as "I will give my father a glass of water when he comes home" and "I want my father to ask about my day." For her mother, she wrote such things as, "I will text my mother if I come home late" and "I want my mother to listen when I share my day" as potential behaviors she wanted to change.

Regarding the meaning of her parents in her life, B wrote the word "mirror" for her father and "shady space" for her mother. She realized that the conflict between herself and her father was founded on their shared characteristics; however, their similarities also sometimes made them feel close to one another. The participant realized that her mother was her protector; her mother's worry was a symbol of love that provided her with a sense of security.

During the final session, the participant reported that she felt more comfortable when she was with her parents, and that she had begun re-engaging in activities with her friends as well as her music activities. The counselor closed the session with a brief psychoeducation about emotions and invited the participant to ask questions. The participant expressed her appreciation to the counselor and said that she hoped to bring in her parents for family counseling. B showed a strong desire for her family to be happy, specifically stating that she felt that her parents carried an emotional burden and might need some help as well. From the measurement results, the counselor noted that B's level of depression symptoms had decreased to a score of eight on the BDI. She also reported no alcohol consumption since the first session.

\section{Follow-up Session}

B reported that she felt fine and much better than before. She was able to apply delayed response techniques when faced with an uncomfortable situation, particularly with her family. B reported having performed one of the simple behaviors that she had listed during 
the last session. Her relationship with her parents was also much improved, with the exception of some argumentative moments. However, she reported that she was still having difficulty disclosing her feelings to others, and tended to keep her problems to herself. This condition resulted in feelings of discomfort with herself and also made decision making difficult for her. B reported no alcohol consumption since the last session, although the urge to consume alcohol remained.

\section{Discussion}

\section{Interpretation}

Emotion dysregulation aims to mediate the link between child abuse/neglect and depressive disorder at the next stage of development (Crow, Cross, Powers \& Bradley, 2014), and it also acts as link between lifetime cumulative adversity and depressive symptoms (Abravanel \& Sinha, 2015). Emotion regulation plays an important role in the individuals' coping distress, particullary during emerging adulthood, a developmental stage during which distress is not only caused by academic demands, but also by peer and romantic relationships (La Greca \& Harrison, 2005). Survey of the American College Health Association (2008) found that more than $18 \%$ of college students reported depression symptoms. The intervention in the current study subtly encouraged the participant to take control of her emotions, so she could better regulate them in the face of distressing situations.

The results of this study included changes in the mood and perspective of the participant. The participant reported mood enhancement and an ability to re-engage in her normal activities, as evidenced by the decrease in depression symptoms from a score of 25 to 8 on the BDI scale. This decline reflects a change in the intensity of depression symptoms, more particularly from a moderate level to a normal level. The study also resulted in a decrease in alcohol consumption from eight to zero times per month. Prior to the intervention, the participant reported consuming about four glasses per alcohol consumption, whereas she reported zero alcohol consumption following the intervention. Such results indicate the effectiveness of the current study's intervention in reducing the participant's distress.

ACT emphasizes a mindfulness approach as the first prominent action in therapy. In the field of emotion regulation, mindfulness might elicit a particular type of emotion regulation strategy called "mindful emotion regulation" (Guendelman, Medeiros \& Rampes, 2017). This strategy relies on bottom-up mechanisms, in contrast to cognitive reappraisal, which relies on a top-down mechanism (Guendelman et al., 2017). Mindful emotion regulation is conceived as a unique emotion regulation strategy that results from encountering diverse emotional states from a mindful mental state, which includes awareness and acceptance (Chiesa, Serretti \& Christian, 2013; Farb \& Segal, 2012; Grecucci, Pappaianni, Siugzdaite \& Theuninck, 2015; Guendelman et al., 2017).

During the first and second sessions, the counselor used active listening techniques; including to posing open-ended questions to allow the participant to express her emotions without concern for criticism. It was important for the participant to ventilate the suppressed emotions that were causing her psychological distress. Reflecting on her feelings also helped the participant to name and validate her emotions, and reflecting on meaning helped the 
participant to clarify the impact of her emotions on herself. Based on the diathesis stress model, outbursts of emotion are caused by the invalidation of emotion; therefore, the basic techniques of counseling helped the participant become more conscious of her emotions, thereby validating them. Mindfulness breathing was additionally provided as a tool that encouraged the participant to be more mindful and aware of her emotional experiences, thereby further resulting in her acceptance of her negative emotions.

The counselor did not pressure the participant to apply a mindfulness technique, but rather gave her the opportunity to explore multiple techniques and determine which of them best suited her. During the practice of mindfulness activities (e.g., deep breathing, yoga breathing, praying), B realized that her primary negative emotion was anger. This realization was stated in the second session. Anger was an unacceptable emotion for B, and it was therefore masked by another negative emotion that she deemed more acceptable, specifically sadness. This sequence of events demonstrates that $\mathrm{B}$ was beginning to become more mindful of her primary emotion, which helped her to identify why the emotion emerged and how suppression impacted her social relationship patterns. Secondary emotions are often destructive and make an individual more vulnerable psychologically (O'Connor, 2006). Therefore, in addition to naming both primary and secondary emotions, it is important for one to learn to accept their primary emotion without condeming themselves for experiencing it. The participant's developing awareness of her emotions, thoughts, and situation helped her to identify her complaints patterns, thereby enabling participant to better understand herself and anticipate the occurrence of the same patterns in the future.

Depression is one of various mood disorders characterized by a failure to adaptively regulate emotion due to heightened emotional reactivity and increased self-focus (Clark, Watson \& Mineka, 1994). These reactions can reduce one's cognitive resources for positively reappraising stressful stimuli (Guendelman et al, 2017). In such situations, mindful emotion regulation may be useful by offering a non-evaluative means by which to attend to negative emotional experiences. Emotional regulation was experienced by B, who in a later session learned to reappraise adserve events, particullary those related to her family, in a more positive manner. These changes in her perspective encouraged her to identify a simple regulatory behavior that was possible for her to apply. The development of a more positive perspective was also demonstrated in the last session, during which she described her parents' meaning in her life. Her success in dealing with her negative emotion and improving her interpersonal relationships reduced her emotional coping through alcohol consumption.

During the follow-up session, B reported improvement in her family relationship, however she also still experienced challenges with makin decisions. Difficulty with decision making is a common problem during emerging adulthood (Arnett, 2007). This problem can impact social adjustment and might lead B to other stressful situations. Social demands during emerging adulthood require young adults to be able to make independent decisions (Arnett, 2007; 2011). A limitation of this intervention is that did not focus on improving B's decision making abilities and social skills, which might lead to B re-experiencing psychological distress when she faces future challenges with social relationship. 


\section{Analysis}

The applied method has some considerable strengths, the first is that the homework assignment was a simple task that could help control motivation factors. Moreover, each session was separated by a long enough time interval that made it possible for the participant to apply the results of the intervention and apply them to her daily life. The results of the intervention were additionally supported by a reliable measurement scale.

\section{Limitation}

In addition to the lack of focus on improving social skills and decision making, several other limitations of the current study should be noted. First, there was no record of homework application frequency or other activities to further document the participant's psychological changes. Such records could potentially help identify additional extraneous variables in the study that should be controlled in future research. Moreover, because this was a single-case study, certain individual factors (i.e., intelligence, personality, and social support) might also have influenced the effectiveness of the intervention. Another limitation is related to the method of measurement; there was no repeated measurement of the baseling and postintervention assessment in this study. A repeated measures approach could be useful for strengthening the internal validity of the study, which could reduce the possibility of temporary mood fluctuations masking substantial changes in the participants throughout the course of the study. These points need to be considered in subsequent research.

\section{Applicability}

The current intervention was conducted in a college counseling setting. The techniques applied in each intervention are relatively convenient, as they entail simple and effortless homework assigned to the participant. Due to their simplicity, the techniques in this study can potentially be applied in school settings with the aid of the respective school counselors. The effectiveness of this intervention can be considered as a possible first aid approach to overcome depression symptoms, particullary in students with symptoms and personal characteristics that are the same or similar to those exhibited by B.

\section{Conclusion}

The study found that emotion acceptance-based intervention can be applied in case B. Mindfulness breathing helped B to cope with perceived negative emotions. The counseling techniques applied by the researcher, specifically active listening, reflection, emotion normalization, and confrontation, also helped B to understand herself and her primary emotion. Moreover, observation tasks assigned as homework helped B to be in the "here-andnow", thereby making her more clearly aware of her emotions, thoughts, and situation, which ultimately helped B to enhance her mood and re-engage in daily activities. This change was followed-upon by a desire to take actions to improve her interpersonal relationships, particullarly with her parents. B's success in dealing with her negative emotions and improving her interpersonal relationships reduced her emotional coping through alcohol consumption. The follow-up findings demonstrated that such positive results could be 
maintained by B after four weeks. Nevertheless, the reported difficulties in decision making should be a focus of future interventions.

\section{Acknowledgement}

The authors would like to thank the Student Counseling Center - at University of Indonesia for providing the facility for us to conduct all of the session. We also would like to thank the participant $\mathrm{B}$ for her cooperation throughout each session and willingness to allow us to used her data in a scientific article.

\section{References}

Abravanel, B. T. \& Sinha, R. (2015). Emotion dysregulation mediates the relationship between lifetime cumulative adversity and depressive symptomatology. Journal of Psychiatric Research. 61, 89-96.

American College Health Association. (2008). National College Health Assessment. Retrieved April 14, 2018, from http://www.acha-ncha.org/index.htm

Arnett, J. J. (2007). Emerging adulthood: What is it, and what is it good for? Child Development Perspectives. $1(2), 68-73$.

Arnett, J. J. (2011). Emerging adulthood(s): The cultural psychology of new life stage. In Bridging Cultural and Developmental Approaches to Psychology: New Syntheses in Theory, Research, and Policy, L.A., Jensen (Ed.). New York, NY: Oxford University Press

Beck, A. T., Steer, R. A., Beck, J. S. \& Newman, C. F. (1993). Hopelessness, depression, suicidal ideation, and clinical diagnosis of depression. Suicide and Life-Threatening Behavior. 23(2), 139-145.

Boden, M. T. \& Gross, J. J. (2013). An emotion regulation perspective on belief change. In The Oxford Handbook of Cognitive Psychology (Ed.), pp. 585-599. New York, NY: Oxford University Press. Retrieved from http://www.oxfordhandbooks.com/abstract/10.1093/oxfordhb/9780195376746.001.0001/oxfordhb9780195376746-e-37

Chiesa, A., Serretti, A., \& Christian, J. J. (2013). Mindfulness: top-down or bottom-up emotion regulation strategy? Clinical Psychology Review. 33(1), 82-96.

Clark, L. A., Watson, D. \& Mineka, S. (1994). Temperament, personality, and the mood and anxiety disorders. Journal of AbnormalPpsychology. 103(1), 103-116.

Cole, P. M., Michel, M. K. \& Teti, L. O. D. (2014). The development of emotion regulation and dysregulation: A clinical perspective. Monographs of the society for research in child development. 59(2-3), 73-102.

Compare, A., Zarbo, C., Shonin, E., Van Gordon, W. \& Marconi, C. (2014). Emotional regulation and depression: a potential mediator between heart and mind. Cardiovascular Psychiatry and Neurology. 14.

Crow, T., Cross, D., Powers, A. \& Bradley, B. (2014). Emotion dysregulation as a mediator between childhood emotional abuse and current depression in a low-income African-American sample. Child Abuse Neglect. 38, 1590-1598.

Davidson, G. C. \& Neale, J. M. (2001). Abnormal Psychology ( $8^{\text {th }}$ ed.). New York, NY: John Willey \& Sons, Inc.

Farb, N. A., Anderson, A. K. \& Segal, Z. V. (2012). The mindful brain and emotion regulation in mood disorders. The Canadian Journal of Psychiatry. 57(2), 70-77.

Forkmann, T., Wichers, M., Geschwind, N., Peeters, F., Van Os, J., Mainz, V. \& Collip, D. (2014). Effects of mindfulness-based cognitive therapy on self-reported suicidal ideation: results from a randomised 
controlled trial in patients with residual depressive symptoms. Comprehensive Psychiatry. 55(8), 18831890.

Forrest, D. (1983). Depression: Information and Interventions for School Counselors. The School Counselor. 30(4), 269-279.

Gilman, S. E., \& Abraham, H. D. (2001). A longitudinal study of the order of onset of alcohol dependence and major depression. Drug and Alcohol Dependence. 63(3), 277-286.

Grecucci, A., Pappaianni, E., Siugzdaite, R., Theuninck, A. \& Job, R. (2015). Mindful emotion regulation: Exploring the neurocognitive mechanisms behind mindfulness. BioMed Research International 2015.

Guendelman, S., Medeiros, S. \& Rampes, H. (2017). Mindfulness and emotion regulation: Insights from neurobiological, psychological, and clinical studies. Frontiers in Psychology. 8(220).

Harris, R. (2009). ACT Made Simple: An Easy-to-Read Primer on Acceptance and Commitment Therapy. Oakland, CA: New Harbinger Publication.

Hasin, D. S., Tsai, W. Y. \& Endicott, J. (1996). Five-year course of major depression: Effects of comorbid alcoholism. Journal of Affective Disorders. 41(1), 63-70

Hayes, S. C., Strosahl, K. D. \& Wilson, K. G. (1999). Acceptance and Commitment Therapy: An Experiential Approach to Behavior Change. New York, NY: Guilford Press.

Hayes, S. C., Strosahl, K. D. \& Wilson, K. G. (2011). Acceptance and Commitment Therapy: The Process and Practice of Mindful Change. New York: Guilford Press.

Joormann, J. (2010). Cognitive inhibition and emotion regulation in depression. Current Directions in Psychological Science. 19(3), 161-166.

Kuwabara, S. A., Van Voorhees, B. W., Gollan, J. K. \& Alexander, G. C. (2007). A qualitative exploration of depression in emerging adulthood: disorder, development, and social context. General Hospital Psychiatry. 29(4), 317-324.

La Greca, A. M. \& Harrison, H. M. (2005). Adolescent peer relations, friendships, and romantic relationships: Do they predict social anxiety and depression? Journal of Clinical Child and Adolescent Psychology. 34(1), 49-61.

O'Connor, R. (2006). Undoing Perpetual Stress: The Missing Connection between Depression, Anxiety, and $21^{\text {st }}$ Century Illness. New York: Penguin Books.

Pettinati, H. M. \& Dundon, W. D. (2011). Comorbid depression and alcohol dependence. Psychiatric Times. 28(6), 1-8.

Plieger, T., Melchers, C., Montag, C., Meermann, R. \& Reuter, M. (2015). Life stress as potential risk factor for depression and burnout. Burnout Research. 2(1), 19-24.

Reeves, M. D. (2007). The effect of invalidation on emotion regulation: An empirical investigation of Linehan's biosocial theory. (Doctoral dissertation). The Florida State University. Retrieved from Proquest Dissertation Publishing.

Regier, D. A., Farmer, M. E. \& Rae, D. S. (1990). Comorbidity of mental disorders with alcohol and other drug abuse. Results from the Epidemiologic Catchment Area (ECA) Study. JAMA. 264(19), 2511-2518.

Rottenberg, J. (2007). Major depressive disorder: Emerging evidence for emotion context intensivity. In Emotion and Psychopathology: Bridging affective and clinical science, J. Rottenberg \& S. L. Johnson (Eds.), pp 151-165. Washington, DC: American Psychological Association.

Sacks, S., Ries, R. K., \& Ziedonis, D. M. (2005). Substance Abuse Treatment for Persons with Co-Occurring Disorders. Psychiatry Publication and Presentation. 232.

Wolgast, M., Lundh, L. G. \& Viborg, G. (2011). Cognitive reappraisal and acceptance: An experimental comparison of two emotion regulation strategies. Behaviour Research and Therapy. 49(12), 858-866. 